\title{
Natural and unnatural history of pulmonary atresia
}

\author{
H Leonard, G Derrick, J O’Sullivan, C Wren
}

\begin{abstract}
Objective-To investigate mortality, cause of death, survival, and quality of life in all types of cardiac malformation with congenital pulmonary atresia.

Design-Retrospective analysis.

Setting-The resident population of one health region with a single tertiary referral centre.

Patients-All babies with pulmonary atresia live born in 1980 to 1995.

Main outcome measures-Anatomical classification, total mortality, cause of death, duration of survival, exercise ability. All cases were classified as pulmonary atresia with intact septum (PAIVS), pulmonary atresia with ventricular septal defect (PA-VSD), or pulmonary atresia with complex cardiac malformation (complex pulmonary atresia).

Results-129 cardiac malformations with congenital pulmonary atresia were identified from 601635 live births (21.4/100 000): 29 had PA-IVS, 60 had PA-VSD, and 40 had complex pulmonary atresia. Total mortality was $72 / 129(56 \%)$, with 15 deaths in the first week and 49 in the first year. There were 23 surgical deaths, 33 hospital deaths (not related to surgery), and 16 sudden deaths, 12 of which remained unexplained. The sudden death rate was 29/1000 patient years of follow up. Of the 57 survivors, 39\% have exercise ability I or II and $61 \%$ III or IV. Definitive surgical repair produced better exercise ability.

Conclusions-Early mortality is high in all types of pulmonary atresia, although survival has improved in recent years. Most children who have not undergone definitive repair have significant exercise limitation.

(Heart 2000;84:499-503)
\end{abstract}

Keywords: congenital heart disease; pulmonary atresia; sudden death; quality of life

Cardiac malformations with pulmonary atresia are rare but occupy a disproportionate amount of cardiological and surgical time and resources. Published reports have been confined to only one type of pulmonary atresia, either with intact ventricular septum ${ }^{1-3}$ or with ventricular septal defect. $^{4-6}$ There is anatomical diversity within both these groups and bias may occur because of variations in anatomical selection criteria. Pulmonary atresia also occurs as part of more complex malformations, and such cases are excluded from other series. ${ }^{235}$ Bias may occur in studies that report surgical series ${ }^{7-11}$ or institution based data, ${ }^{12-15}$ because of early deaths occurring before referral and inclusion of late referrals from other centres.

In this retrospective study we describe the outcome of all live born babies with pulmonary atresia within a defined population. Population based data give a more accurate picture of overall outcome than surgical series, institution based series, or reports limited to one variety of pulmonary atresia. They are thus important for planning management.

Department of
Paediatric Cardiology,
Freeman Hospital,
Newcastle upon Tyne
NE7 7DN, UK
H Leonard
G Derrick
J O'Sullivan
C Wren
Correspondence to:
Dr Leonard email:
Christopher.Wren@
tfh.nuth.northy.nhs.uk
Accepted 3 May 2000

Department of

Paediatric Cardiology, Newcastle upon Tyne NE7 7DN, UK

J O'Sullivan

Correspondence to:

Dr Leonard email:

Christopher.Wren

Accepted 3 May 2000

\section{Methods}

PATIENT IDENTIFICATION

The former Northern Health Region of England is geographically well defined and has a population of approximately three million. There is only one tertiary referral centre for paediatric cardiology and, with the exception of the health district of South Cumbria, which was excluded from this study, there is no cross border referral of infants with suspected heart disease. ${ }^{16}$

Patients were identified from the paediatric cardiology database, the Northern Region perinatal mortality survey, ${ }^{17}$ the Northern Region congenital abnormality survey, ${ }^{18}$ and fetal echocardiography records. The use of several sources allowed validation of data and ensured identification of any deaths occurring before referral to the regional cardiology centre. The total live birth rate for the region was obtained from the Office for National Statistics.

Patients included were those live born in 15 of the 16 districts of the Northern Health Region between 1980 and 1995 with congenital pulmonary atresia. Six pregnancies were terminated after antenatal diagnosis (four with additional non-cardiac malformations) and were excluded from the study.

ANATOMICAL CLASSIFICATION

Information about cardiac anatomy, age at diagnosis, interventions, and death was obtained from review of patient records and necropsy reports. Pulmonary arteries were classified by size (absent, small, or normal) and confluence (whether the right and left pulmonary arteries communicate directly with each other). The source of pulmonary blood supply (through the arterial duct or major aortopulmonary collaterals) and the presence of coronary artery fistulae were recorded. Retrospective analysis did not permit more accurate grading of pulmonary artery size (and was not possible in four cases) or measurement of right ventricular volume or tricuspid valve diameter. ${ }^{1}$

Patients were divided into three groups: those with intact ventricular septum (PA-IVS), those with ventricular septal defect (PA-VSD), and those with more complex malformations (complex pulmonary atresia). Patients were 
Table 1 Cardiac diagnoses in complex pulmonary atresia

\begin{tabular}{ll}
\hline & $\begin{array}{l}\text { Number of } \\
\text { patients } \\
\text { (survivors) }\end{array}$ \\
\hline Atrial isomerism & $8(1)$ \\
Congenitally corrected transposition & $6(5)$ \\
Complete atrioventricular septal defect & $5(1)$ \\
Ebstein's anomaly & $5(0)$ \\
Tricuspid atresia & $4(2)$ \\
Mitral atresia & $4(2)$ \\
Double inlet left ventricle & $3(1)$ \\
Other & $5(2)$ \\
\hline
\end{tabular}

included in the PA-IVS group if the ventricular septum was intact and there were normal atria and atrioventricular connections. Those with additional Ebstein's malformation of the tricuspid valve and severe right ventricular dilatation were classified as complex pulmonary atresia (see below). Patients were included in the PA-VSD group if there was a ventricular septal defect with normal atria, atrioventricular valves, and atrioventricular connection, irrespective of ventriculoarterial connection. This group included cases described as tetralogy of Fallot with pulmonary atresia, transposition with pulmonary atresia, or double outlet right ventricle with pulmonary atresia, and included cases with major aortopulmonary collateral vessels irrespective of their contribution to pulmonary blood supply. Cases where pulmonary blood supply is entirely derived from aortopulmonary collateral vessels have been termed "complex pulmonary atresia" in other studies. ${ }^{4}$ We reserved this description for cases that did not fit into the first two recognised groups because of abnormalities of atria, atrioventricular valves, and atrioventricular or pulmonary venous connections (table 1 ).

\section{INTERVENTION}

We considered palliative procedures to include total cavopulmonary connection, Fontan, Glenn, aortopulmonary shunt and stenting, ligation, or unifocalisation of major aortopulmonary collaterals.

EXERCISE ABILITY

Current exercise ability in survivors was assessed by a telephone questionnaire administered to parents of patients. Three patients with limitations because of non-cardiac problems and one

Table 2 Mortality related to anatomical variation in pulmonary atresia associated with ventricular septal defect

\begin{tabular}{|c|c|c|c|c|c|c|}
\hline & \multicolumn{3}{|c|}{ Survival at 1 year } & \multicolumn{3}{|c|}{ Survival at end of study } \\
\hline & $\begin{array}{l}\text { Alive } \\
(n=45)\end{array}$ & $\begin{array}{l}\text { Dead } \\
(n=15)\end{array}$ & $p$ Value & $\begin{array}{l}\text { Alive } \\
(n=32)\end{array}$ & $\begin{array}{l}\text { Dead } \\
(n=28)\end{array}$ & $p$ Value \\
\hline \multicolumn{7}{|l|}{ MAPCAS } \\
\hline Present & 24 & 6 & & 19 & 11 & \\
\hline Absent & 21 & 9 & $>0.3$ & 13 & 17 & $>0.1$ \\
\hline \multicolumn{7}{|c|}{ Pulmonary artery size ${ }^{\star}$} \\
\hline Absent & 3 & 2 & $>0.5 \dagger$ & 3 & 2 & $>0.6 \dagger$ \\
\hline Reduced & 21 & 6 & $>0.7 \ddagger$ & 14 & 13 & $>0.6 \ddagger$ \\
\hline Normal & 21 & 5 & & 15 & 11 & \\
\hline \multicolumn{7}{|l|}{ Pulmonary arteries } \\
\hline Confluent & 40 & 13 & & 28 & 25 & \\
\hline Non-confluent & 5 & 2 & $>0.8$ & 4 & 3 & $>0.8$ \\
\hline
\end{tabular}

$\star$ Unknown in two cases.

†Absent + reduced $v$ normal

$\ddagger$ Reduced $v$ normal.

MAPCAS, major aortopulmonary collaterals. with PA-IVS who had undergone cardiac transplantation were excluded from this analysis. Each child's exercise ability was described by one of the following categories: (I) unlimited compared with peers; (II) tires before peers during sports or games but unlimited when walking on level ground; (III) needs to stop and rest when walking on level ground; (IV) symptomatic at rest or on minimal exertion.

\section{STATISTICS}

Actuarial survival was calculated using the Kaplan-Meier technique. ${ }^{19}{ }^{20}$ The $\chi^{2}$ method was used to compare mortality related to anatomical variations in the PA-VSD group (table 2).

\section{Results}

\section{PREVALENCE AT LIVE BIRTH}

Between 1980 and 1995 there were 129 cases of pulmonary atresia among 601635 live births: 29 with PA-IVS (4.8/100 000), 60 with PA-VSD (10.0/100 000), and 40 with complex pulmonary atresia (6.6/100 000) — a total birth prevalence of 21.4/100 000 live births.

The median time to follow up (or death) was 1252 days (range $1-6119$ days). The minimum follow up of survivors was two years, providing a total of 555 patient years follow up. Figure 1 provides a graphical representation of survival and changing pattern of survival in each diagnostic group.

\section{MORTALITY}

The total mortality of the group was $72 / 129$ $(56 \%)$. Mortality in the first year of life was 49/129 (38\%): 15/29 (52\%) for PA-IVS, $15 / 60$ (25\%) for PA-VSD, and 19/40 (48\%) for complex pulmonary atresia. There were 15 deaths within the first week, eight of which occurred before surgical intervention could be offered. Kaplan-Meier survival plots are shown in fig 2.

For patients with PA-VSD, neither the presence nor absence of major aortopulmonary collateral vessels nor pulmonary artery size or confluence could be shown to have any influence on survival (table 2). The three surviving patients with no central pulmonary arteries had interventions: MAPCA (major aortopulmonary collateral arteries) stent (one patient) and shunt to vessels at lung hilum (two patients). The two who died had no intervention.

\section{CAUSE OF DEATH}

The cause of death was classified in three groups: deaths related to surgery, deaths in hospital from non-surgical causes, and sudden out of hospital deaths (table 3).

\section{Surgical deaths}

There were 23 surgical deaths (after 191 surgical procedures). They were defined as deaths in hospital within 30 days of surgery, but all except four occurred in the first 24 hours. In the PA-IVS group there were six deaths at a mean age of 65 days (range 3-345). In the PA-VSD group there were seven deaths at a mean age of 1209 days (range 3-2558). In the complex pulmonary atresia group there were 10 deaths at a mean age of 446 days (range 1-2278). 

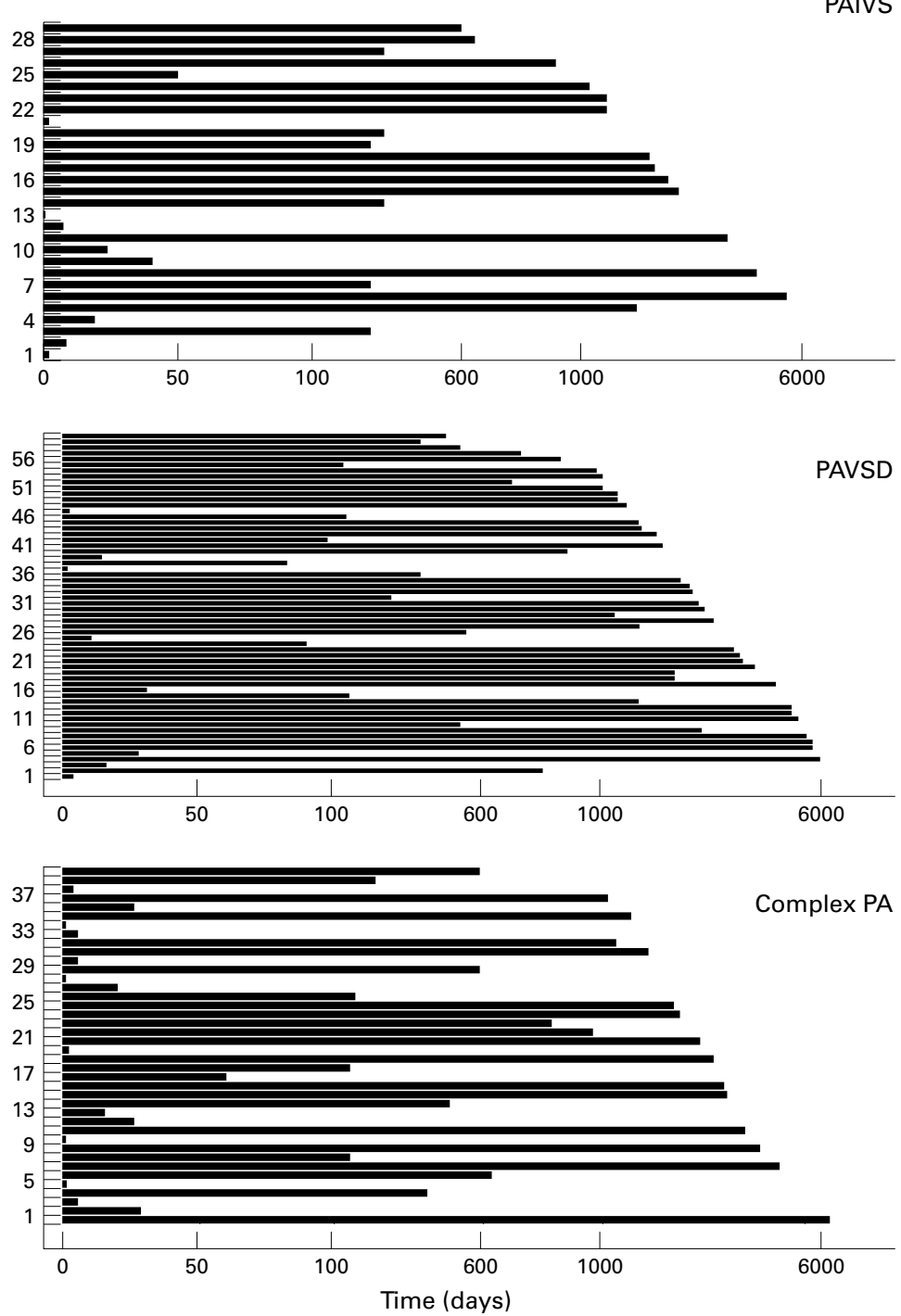

Figure 1 Survival plots for patients in all three groups. The length of the line shows time to follow up or death (in days). Patients are plotted in birth order on the y axis so that line stopping short of the right hand outline indicate death, while those reaching the right hand outline indicate survival at latest follow up. Note that a three step linear scale is employed, as a logarithmic or linear scale would distort the plot.

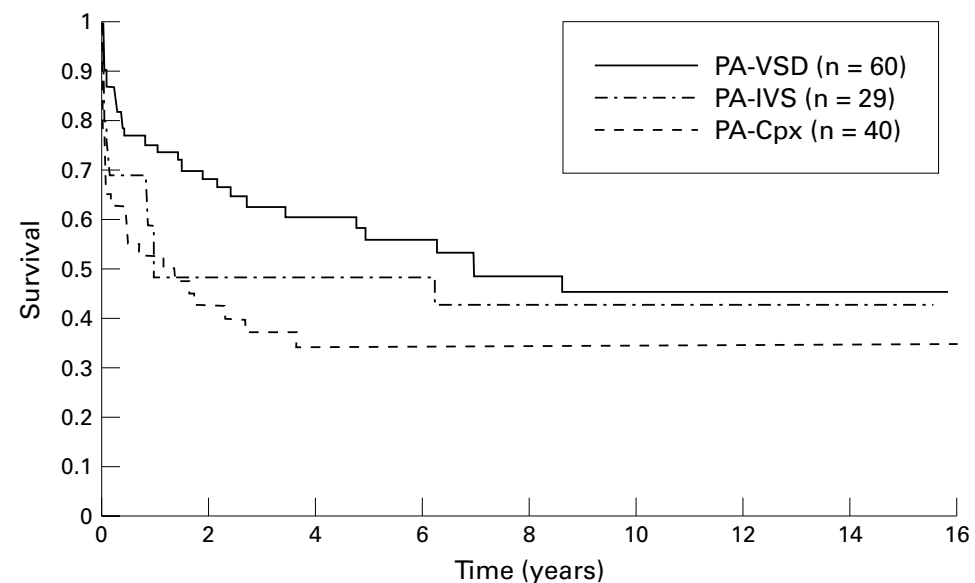

Figure 2 Kaplan-Meier survival plot for pulmonary atresia with intact septum (PA-IVS), pulmonary atresia with ventricular septal defect (PA-VSD), and complex pulmonary atresia (PA-CPX).
Hospital deaths

Thirty three deaths occurred in hospital but were not related to surgery. Most occurred in children under one year of age and they were primarily cardiac in origin, although there were often added problems such as infection. Eight deaths were from non-cardiac problems: six patients (two in each group) died because of immunodeficiency and sepsis, and two neonates with complex pulmonary atresia died from pulmonary hypoplasia.

In the PA-IVS group there were seven deaths at a mean age of 127 days (range 1-345). In the PA-VSD group there were 14 deaths at a mean age of 421 days (range $1-2555)$. In the complex pulmonary atresia group there were 12 deaths at a mean age of 47 days (range 1-252).

\section{Sudden deaths}

Sixteen patients suffered sudden unexpected collapse and died before or shortly after arrival at hospital. Twelve of these 16 deaths remained unexplained after necropsy.

Three children with PA-IVS died suddenly at a mean age of 975 days (range 297-2279). All deaths were unexplained at necropsy. Seven children with PA-VSD died suddenly at a mean age of 850 days (range 90-3315). Five deaths were unexplained at necropsy; one child had severe gastroenteritis and one had a large pulmonary haemorrhage. Six children with complex pulmonary atresia died suddenly at a mean age of 590 days (range 26-1333). Four deaths were unexplained at necropsy; one was caused by occlusion of an aortopulmonary shunt and one infant had undiagnosed obstructed anomalous pulmonary venous connection.

Fifteen of the 16 patients who died suddenly had undergone previous surgery; 14 with an aortopulmonary and one with a Glenn shunt in situ. Only one had an occluded shunt at necropsy.

\section{CURRENT STATUS}

Non-cardiac anomalies that have an additional effect on their quality of life are present in 14 of the 72 survivors (19\%). One child with PA-IVS had renal pelviureteric junction obstruction requiring surgery. Ten children with PA-VSD have the following problems: Di George syndrome (two), Alagille's syndrome, Shprintzen's syndrome, Coffin Lowry syndrome, mild hemiparesis (two), idiopathic thrombocytopenia, epilepsy, and choledochal cyst. In the complex pulmonary atresia group, two survivors have scoliosis and one has chronic glomerulonephritis.

CURRENT EXERCISE ABILITY IN SURVIVORS Attempts were made to contact survivors (except four who were excluded from this analysis) and were successful in 44 of 53 cases $(83 \%)$. Overall 12 children $(27 \%)$ were in class I, five $(11 \%)$ in class II, $25(57 \%)$ in class III, and two $(5 \%)$ in class IV. Details of exercise ability in individual diagnostic groups are given in table 4.

Children who had undergone definitive biventricular repair had a better exercise capacity 
Table 3 Cause of death by age

\begin{tabular}{|c|c|c|c|c|c|c|}
\hline & \multicolumn{2}{|l|}{ Surgical } & \multicolumn{2}{|l|}{ Hospital } & \multicolumn{2}{|l|}{ Sudden } \\
\hline & $<1$ year & $>1$ year & $<1$ year & $>1$ year & $<1$ year & $>1$ year \\
\hline PA-IVS & 6 & - & 7 & - & 2 & 1 \\
\hline PA-VSD & 3 & 4 & 10 & 4 & 2 & 5 \\
\hline Complex PA & 5 & 5 & 12 & - & 2 & 4 \\
\hline
\end{tabular}

IVS, intact interventricular septum; PA, pulmonary atresia; VSD, ventricular septal defect.

Table 4 Exercise ability in individual diagnostic groups

\begin{tabular}{lrrrl}
\hline Exercise ability & $I$ & $I I$ & $I I I$ & $I V$ \\
\hline PA-IVS & 4 & 1 & 2 & 0 \\
PA-VSD & 6 & 2 & 15 & 2 \\
Complex PA & 2 & 2 & 8 & 0 \\
Total & 12 & 5 & 25 & 2
\end{tabular}

IVS, intact interventricular sptum; PA, pulmonary atresia; VSD, ventricular septal defect. For exercise ability grades see text.

Table 5 Relation between exercise ability and postoperative status

\begin{tabular}{llll}
\hline & & \multicolumn{2}{l}{ Exercise ability } \\
\cline { 3 - 4 } & & $I+I I$ & $I I I+I V$ \\
\hline \multirow{2}{*}{ PA-IVS } & 2V & 4 & 0 \\
& IV & 1 & 0 \\
PA-VSD & Palliation & 0 & 2 \\
& 2V & 4 & 0 \\
\multirow{2}{*}{ Complex PA } & 1V & 0 & 2 \\
& Palliation & 4 & 15 \\
& 2V & 0 & 0 \\
& 1V & 3 & 2 \\
& Palliation & 1 & 6 \\
\hline
\end{tabular}

IVS, intact interventricular septum; PA, pulmonary atresia; VSD, ventricular septal defect.

$2 \mathrm{~V}$, biventricular repair; $1 \mathrm{~V}$, Fontan operation or equivalent; palliation, other palliative procedure or no intervention.

than those who had had palliative operations or no intervention (table 5).

\section{Discussion}

Published reports on pulmonary atresia are usually either surgical series ${ }^{7-11}$ or based on experience from a single institution. ${ }^{15}$ Data from institutions with a particular interest in the diagnosis will attract a disproportionate amount of more complicated referrals and introduce bias. Surgical series ignore cases where death occurs before intervention or where no intervention was feasible or thought necessary.

Most studies deal either with PA-IVS or PA-VSD and very few consider pulmonary atresia associated with other malformations. The anatomical inclusion or exclusion criteria vary (for example, hearts with Ebstein's malformation of the tricuspid valve may be included or excluded from series on PA-IVS), and apparently similar reports may not be comparable. ${ }^{1-3}$ Complex pulmonary atresia is usually considered under the main associated cardiac malformation, even though the management (often aiming for a Fontan type circulation) is usually independent of the associated malformation. A recent report considering diagnostic hierarchies has shown that use of pulmonary atresia as a secondary diagnosis, as in our complex pulmonary atresia group, leads to an underascertainment of $27 \%{ }^{21}$

Our prevalence at live birth of PA-IVS $(4.8 / 100000)$ is consistent with the value of 4.5/ 100000 live births found in the only other published detailed population based study. ${ }^{22}$ How- ever, we cannot really compare our total prevalence at live birth of all pulmonary atresia (21.4/1000 live births) with any previous reports. Population based epidemiological studies such as the New England infant cardiac program $^{23}$ and the Baltimore Washington infant study $^{24}$ do not define pulmonary atresia and have been criticised for underascertainment.

The present study provides details of mortality and survival for all types of pulmonary atresia in a birth cohort with complete ascertainment. This information is important when planning management after antenatal or postnatal diagnosis. Doctors counselling parents following an antenatal diagnosis sometimes only have a diagnosis of pulmonary atresia, with little additional anatomical data. The study shows the high early mortality in all three groups, especially PA-IVS and complex pulmonary atresia, with only about $50 \%$ medium term survival. In recent years there has been an improvement in survival in PA-IVS, little change in PA-VSD, and no improvement in complex pulmonary atresia (fig 1). Almost all the hospital non-surgical deaths and most of the surgical deaths occurred within the first year of life.

The incidence of out of hospital sudden death was surprisingly high, at 29/1000 patient years of follow up. This is much higher than reported after atrial repair of transposition of the great arteries or repair of tetralogy of Fallot. ${ }^{25}$ Sudden death was encountered in all three groups, and 12 of 16 such deaths remained unexplained after necropsy. None of these three groups has previously been identified as having a significant risk of sudden death.

The exercise ability of survivors is disappointing, with three in four reporting limitation compared with their peers. As discussed above, some survivors have non-cardiac problems that also affect their quality of life. The exercise ability of children who have achieved biventricular repair is better than with a single ventricle repair or palliation. Some of the younger children currently palliated will undergo later definitive repair.

This study spans a period with considerable changes in management. Our own institutional bias has been towards conservative management, particularly in the early years of the study. These findings may indicate that a more aggressive surgical approach may be required.

\section{CONCLUSIONS}

Cardiac malformations with pulmonary atresia constitute a small proportion of congenital heart disease but require a large amount of medical attention. Despite this, results remain disappointing. Efforts to improve the outcome may be limited by early deaths before surgery, associated non-cardiac conditions, and late sudden death.

We are indebted to the Children's Heart Unit Fund for financial support of the paediatric cardiology database and to Kati Whiteoak for data collection. We are also grateful to Kathryn Breeze and Sheila Jamieson for producing the figures.

1 Bull C, Kostelka M, Sorensen K, et al. Outcome measures for the neonatal management of pulmonary atresia with 
intact ventricular septum. I Thorac Cardiovasc Surg 1994;107:359-66.

2 Hanley FL, Sade RM, Blackstone EH, et al. Outcomes in neonatal pulmonary atresia with intact ventricular septum: a multi-institutional study. F Thorac Cardiovasc Surg 1993; 105:406-23.

3 Jehangirir M, Zurakowski D, Bichell D, et al. Improved results with selective management in pulmonary atresia with intact ventricular septum. F Thorac Cardiovasc Surg 1999;118:1046-53

4 Bull K, Somerville J, Ty E, et al. Presentation and attrition in complex pulmonary atresia. I Am Coll Cardiol 1995;25: 491-9.

5 Dinarevic S, Redington A, Rigby M, et al. Outcome of pulmonary atresia and ventricular septal defect during infancy. Pediatr Cardiol 1995;16:276-82.

6 Hofbeck M, Sunnegard JT, Burrows PE, et al. Analysis of survival in patients with pulmonic valve atresia and ventricular septal defect. Am f Cardiol 1991;67:737-43.

7 Rychik J, Levy H, Gaynor JW, et al. Outcome after operations for pulmonary atresia with intact ventricular operations for pulmonary atresia with intact ventric
septum. F Thorac Cardiovasc Surg 1998;116:924-31.

8 Najm HK, Williams WG, Coles JG, et al. Pulmonary atresia with intact ventricular septum: results of the Fontan procedure. Ann Thorac Surg 1997;63:669-75.

9 Mair DD, Julsrud PR, Puga FJ, et al. The Fontan procedure for pulmonary atresia and intact ventricular septum: operative and late results. F Am Coll Cardiol 1997;29:1359-64.

10 Reddy VM, McElhinney DB, Silverman NH, et al. Partia biventricular repair for complex congenital heart defects: an intermediate option for complicated anatomy of functionally borderline right complex heart. $\mathcal{F}$ Thorac Cardiovasc Surg 1998;116:21-7.

11 Miyaji K, Shimada M, Sekiguchi A, et al. Pulmonary atresia with intact ventricular septum: long-term results of "one and a half" ventricular repair. Ann Thorac Surg 1995;60: $1762-4$.

12 Hadjo A, Jimenez M, Baudet E, et al. Review of the long term course of 52 patients with pulmonary atresia and ven-
tricular septal defect. Anatomical and surgical considerations. Eur Heart f 1995;16:1668-74.
13 Coles JG, Freedom RM, Lightfoot NE, et al. Long term results in neonates with in pulmonary atresia and intact ventricular septum. Ann Thorac Surg 1989;47:213-17.

14 Leung M, Mok C, Lee J, et al. Management and evolution of pulmonary atresia and intact ventricular septum. Am $\mathcal{F}$ Cardiol 1993;71:1331-6.

15 Luciani GB, Swilley S, Starnes VA. Pulmonary atresia, intact ventricular septum, and major aortopulmonary collaterals: morphogenetic and surgical implications. 7 Thorac Cardiovasc Surg 1995;110:853-4.

16 Wren C, Richmond S, Donaldson L. Presentation of congenital heart disease in infancy: implications for routine examination. Arch Dis Child 1999;80:F49-53.

17 Northern Regional Health Authority Coordinating Group. Perinatal mortality; a continuing collaborative regional group. BMF 1984;288:1717-20.

18 Northern Regional Survey Screening group. Fetal abnormality, an audit of its recognition and management. Arch Dis Child 1992;67:F770-4.

19 Bland JM, Altman DG. Survival probabilities (the KaplanMeier method). BMF 1998;317:1572

20 Healy M. Survival data. Arch Dis Child 1995;73:374-7.

21 Ferencz C, Rubin JD, McCarter RJ, et al. Congenital heart disease: prevalence at live birth. The Baltimore Washington infant study. Am F Epidemiol 1985;121:31-6.

22 Daubeney PE, Sharland GK, Cook AC, et al. Pulmonary atresia with intact ventricular septum: impact of fetal echocardiography on incidence at birth and postnatal outcome. UK and Eire collaborative study of pulmonary atresia with intact ventricular septum. Circulation 1998;98:562-6.

23 Fyler DC. Report of the New England infant cardiac program. Pediatrics 1980;65(suppl):377-461.

24 Wren C, Richmond S, Donaldson L. Temporal variability in birth prevalence of cardiovascular malformations. Heart 2000;83:414-9.

25 Silka MJ, Hardy BG, Menashe VD, et al. A population based prospective evaluation of risk of sudden cardiac death after operation for common congenital heart defects. $\mathcal{F} \mathrm{Am}$ Coll Cardiol 1998;32:245-51.

\section{IMAGES IN CARDIOLOGY}

\section{Multiple milking in hypertrophic cardiomyopathy}

A 70 year old man with recent onset angina and deep $\mathrm{T}$ wave inversion on the lateral leads was referred for cardiac catheterisation. At angiography (lateral projection: A, diastole; B, systole) no coronary stenoses were found, but "multiple milking" of the mid left anterior descending coronary artery (up to $70 \%$ systolic narrowing, large arrow) and on the mid segment of two relatively large diagonal branches (both with 100\% systolic narrowing, small arrows) was revealed. In addition, severe compression - with systolic disappearance-of three septal perforator branches was also visualised. Two dimensional (cross sectional) echocardiography disclosed asymmetric septal hypertrophy (anterior septum $22 \mathrm{~mm}$, posterior wall $10 \mathrm{~mm}$ ) with severe and diffuse involvement of the entire interventricular septum and anterolateral wall. No intraventricular gradient could be elicited at rest or after provocation. Dobutamine stress echocardiography was negative for ischaemia.

FERNANDO ALFONSO RAMÓN CASTRO CARLOS ALMERÍA
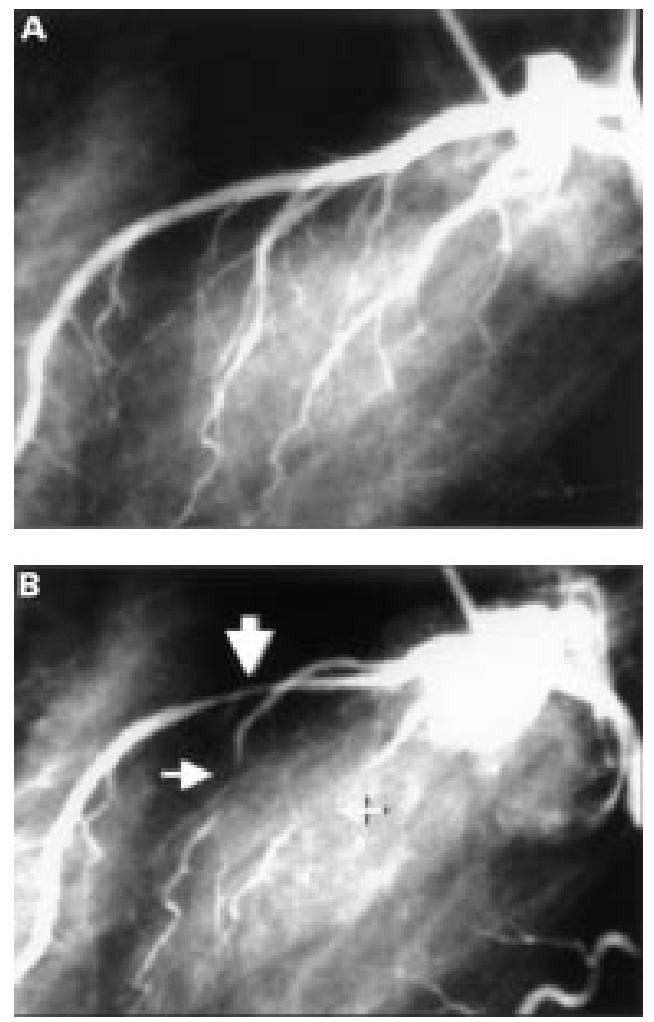